\title{
Diagnosis of Hepatitis using Adaptive Neuro-Fuzzy Inference System (ANFIS)
}

\author{
Rahmon Ibrahim \\ Babcock University \\ Dept. of Computer Science \\ llisan Remo, Ogun State, Nigeria
}

\author{
Omotosho Olawale \\ Babcock University \\ Dept. of Computer Science \\ llisan Remo, Ogun State, Nigeria
}

\author{
Kasali Funmilayo \\ Babcock University \\ Dept. of Computer Science \\ llisan Remo, Ogun State, Nigeria
}

\begin{abstract}
Hepatitis B is one of the liver diseases that is difficult to discover at an early stage of its attack and prominent public health problem. As at 2017, medical statistic recorded that over 23 million of Nigerians were living with Hepatitis B. Several decision support systems used in diagnosing liver diseases derived their efficiencies from artificial intelligence techniques in tackling the challenges facing physician in respect to complexity of the numerous variables involved in liver diseases diagnosis. In this paper, Adaptive Neuro-Fuzzy Inference System (ANFIS) was employed to invoke neural network that provided structures for fuzzy inference engine (FIE) in order to learn information about the normalized dataset on hepatitis B. The neural network (NN) triggers backpropagation and least square methods for tuning the membership functions at the fuzzification stage while the center of area (COA) was used as defuzzification method to compute the weighted average of the fuzzy set and intensity level of the disease for each record. The system was implemented with technical computing language, MATHLAB, on a dataset that consists of 155 instances and 20 attributes of which only the most five liver function tests (LFTs) attributes were selected as input parameters and the corresponding linguistic values and intensity levels were generated as output in order to identify the severity level of the infection. After the system was evaluated, the performance metric gave accuracy of $90.2 \%$.
\end{abstract}

\section{General Terms}

Neural Networks, Fuzzy Logic, Linguistic Values, Liver Function Test, Adaptive Neuro-Fuzzy Inference System

\section{Keywords}

Hepatitis B, Intensity Level, Decision Support System

\section{INTRODUCTION}

The relevance of intelligence systems in medical diagnosis is tremendously increasing. Information taken from patients and decisions of experts are the most important factors in diagnosis of diseases (Neshat and Zadeh, 2013). The increase in scientific knowledge and computer technology is of great benefits to medical practitioners, in diagnosing lifethreatening diseases and administering treatment for patients. The most commonly known liver disease, hepatitis B is a condition when a liver is inflamed as a result of viral infection. Among the possible causes are wrong intake of medications and drugs, toxins, and excessive alcohol. Hepatitis B could also be transmitted through infectious body fluids and sexual intercourse with infected person (Friedman, 2004).

Artificial intelligence in medicine is essentially concerned with the development of artificial-based techniques programs that relate disease entities with patients' symptoms in form of a model in order to provide a basis for series of diagnosis and precise therapy recommendations for medical management. Numerous researches have shown that, the most successful applications in artificial intelligence (AI) are clinical decision support system used to diagnose patients with liver and kidney related diseases (Neshat and Yaghobi, 2009).

Neuro-fuzzy is an integral aspect of artificial intelligence, which combines the strength of neural network and fuzzy logic together by utilizing the approximation method of neural-network to compute the parameters of a fuzzy system (Obi and Imianvan, 2011). Obviously, medical field has explored a quite number of techniques and methods provided by artificial intelligence for emergency care units and surgical operations Yardimci (2001). Several researches have been conducted on fuzzy-based expert system for diagnosis of diseases while neural network models have also been explored by experts for prediction and classification of liver diseases diseases.

The task of disease diagnosis and management is complex because of the numerous variables involved. The traditional method of diagnosing liver diseases is characterized with a lot of subjective decision-making, and logical thinking of medical practitioners, which lead to inappropriate use of inefficient tool (Smita et al. 2012). One of the key problems encountered in the medical field during the course of delivering proper diagnosis of liver disease is the inability of the physicians to derive comprehensive information as a result of available imprecise medical data set.

Therefore, in this paper, an Adaptive Neuro-Fuzzy Inference System (ANFIS) based model is being used to develop architecture model as problem solving for classifying and determining the intensity levels of hepatitis liver disease. The main objectives are to implement and evaluate the proposed architecture model with performance metrics. The general architecture of ANFIS as a classifier model is presented in Section 2. In Section 3, few related works regarding the use of Neural Network, Fuzzy Logic and Neuro- Fuzzy model based architecture in diagnosing liver diseases are reviewed. while the methodology adopted for the proposed architecture model is systematically presented in Section 4 . In section 5 , the metrics used to evaluate the performance of the proposed model are presented while the implementation and discussion of results are drawn in section 6 .

\section{OVERVIEW OF ANFIS}

\section{ARCHITECTURE MODEL}

ANFIS adopt a neural network technique that can adjust the membership functions parameters and linguistic rules directly from data in order to enhance the system performance. The ANFIS architecture contains a five-layer feedforward neural 
network as shown in Figure 1. ANFIS is a hybrid intelligent system which implements a Sugeno fuzzy inference system for a systematic approach to generating fuzzy rules from a given input-output dataset (Negnevitsky, 2005).

In the forward pass, neuron outputs are calculated layer by layer and the consequent parameters are identified by the least squares estimator (LSE) to obtain the final single output. The forward pass operation on each layer is described below:

Layer 1: Known as a fuzzification layer, define the membership grades for each set of input and depends on the fuzzy membership function chosen. For example, Gaussian MF the output of the ith node of Layer 1 is

$\mathrm{O}_{1},{ }_{\mathrm{i}}=\mu_{\mathrm{Ai}}(\mathrm{x})=\exp \left(-\frac{1}{2}\left(\frac{x 1-c \mathrm{i}}{\sigma i}\right)^{2}\right)$

Where the parameter $\{\sigma i, c i\}$ is called a premise parameter set, the centre and width of the ith fuzzy set $\mathrm{A}_{\mathrm{i}}$, respectively.

Layer 2: Is the output nodes are the firing strength of the rule as the product of the membership grades.

$\mathrm{O}_{2}, \mathrm{i}=\mathrm{w}_{\mathrm{i}}=\mu_{\mathrm{Ai}}(\mathrm{x} 1) * \mu_{\mathrm{Bi}}(\mathrm{x} 2)$

Layer 3: This is called the 'normalised firing strengths', where the output of the ith nodes equals the ratio of the ith rule's firing strength to the sum of all rules' firing strength.

Layer 4: $\mathrm{i}^{\text {th }}$ nodes output is

$\mathrm{O}_{4}, \mathrm{i}=\ddot{\mathrm{w}}_{\mathrm{i}} \mathrm{f}_{\mathrm{i}}=\ddot{\mathrm{w}}\left(\mathrm{p}_{\mathrm{i}} \mathrm{x}+\mathrm{q}_{\mathrm{i}} \mathrm{y}+\mathrm{r}_{\mathrm{i}}\right)$

where $\mathrm{p}, \mathrm{q}$, and $\mathrm{r}$ is a set of consequent parameters which can be identified using the Least Square Estimation (LSE).

Layer 5: The single output, calculates the overall output as the summation of all incoming signals, represented as

$\mathrm{O}_{5}, \mathrm{i}=\sum_{i}$ ẅifi

The LSE is used to minimise the squared error $\|\mathrm{AX}-\mathrm{B}\|^{2}$, where $\mathrm{A}$ is the outputs produced by Layer 3, B is a target output and $\mathrm{X}$ is the unknown consequent value which can be obtained using pseudo-inverse of $\mathrm{X}$ :

$$
X^{*}=\left(A^{T} A\right)^{-1} A^{T} B
$$

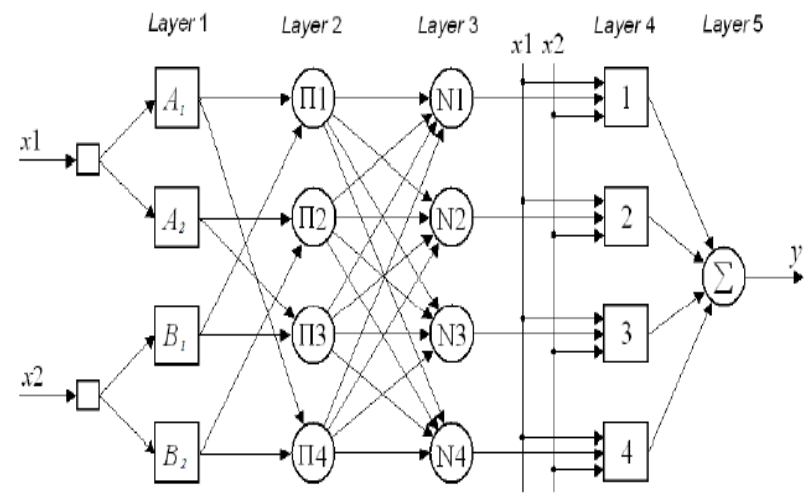

Figure 1: Adaptive Neuro-Fuzzy Inference System (Jang, 1993)

\section{REVIEW OF RELATED WORKS}

There is no doubt about the numerous researches that have been carried out in the area of artificial intelligence in medicine. A tremendous advancement in software and hardware industries has provided opportunities for computer scientist researchers to explore every aspect of artificial intelligence methods and techniques in building relevant systems, and devices for medical practioners. Karthikkalyan (2014) demonstrated a framework built with ANN and multilayer perceptron that classified liver diseases with improved accuracy performance. The model inputs were obtained from liver ultrasound images and employed MLP to detect the traits of any liver disease. In the study, the training of the dataset yielded $90 \%$ while testing validation yielded 95\%. Olaniyi and Adnan (2013) designed an artificial neural network based model that used back propagation neural network based model that used backpropagation method of 10 hidden neurons and radial basis neural network of 20 hidden neurons, with only 6 inputs and one output to diagnose liver diseases into healthy and unhealthy liver. The dataset was obtained from BUPA in UCI Machine Learning Repository and the proposed model achieved $63 \%$ accuracy using backpropagation and $70 \%$ accuracy using radial basis technique. A similar work was proposed in Bahramirad et al. (2013), with the same input attributes and technique, the accuracy of $73 \%$ and $67 \%$ were obtained for radial basis and backpropagation technique respectively.

A group of patients CT liver images was evaluated in Obayya et al (2016) ANFIS model that was used to classify liver tumor as benign or malignant. In their work, the CT liver images passed through various transformation stages such as; enhancement and improvement of image quality as the first stage, the use of extraction algorithms based on thresholding for extraction of liver as the input for the fourth stage where the ANFIS classifier trained the extracted features using back propagation gradient descent method and least square method. The two types of features i.e (texture feature and discrete wavelet transformation) were used separately to evaluate the performance of the model. DWT features recorded 96\% accuracy while the texture feature obtained an accuracy of 90\%. In the proposed Adaptive Neuro Fuzzy Inference System (ANFIS) of Rajamani and Rathika (2015), the primary objective of the model was tailored toward detection of liver cancer in patients with the help of 2-D CT images as input parameters through ANFIS algorithm to generate final optimal result. The summary of other related works are presented in Table 1. Deductions from the reviewed literature are as followed;

i. The hybridized models have better accuracy performance than individual technique base models.

ii. Most of the output of the existing models only classified as the presence or absence of liver disease.

The computation of the intensity levels of the identified liver diseases are ignored in the existing models which serve as a notable gap found in the existing paper.

\section{THE METHODOLOGY FOR THE} PROPOSED MODEL

The adopted methodology for this study is divided into three major phases:
A. Dataset description
B. Linguistic variables definition 
C. Preprocessing of linguistic values (Input parameters)

D. Neuro-Fuzzy engine i.e. ANFIS

- Fuzzy engine

- Neural Network (NN)

The proposed architecture model is presented in Figure 2. In Fig. 2, the liver function test in the dataset for hepatitis disease is normalized in order to re-scale the selected five attributes values in the dataset into the range of 0 and 1 through normalization function. Specific percentage values are assigned independently for both training and testing data before the ANFIS invokes neural network (NN) to provide structures for fuzzy inference engine to learn information about the normalized data. The neural network triggers backpropagation and least square methods in order to tune the Gaussian membership function at the fuzzification stage to design fuzzy set for the linguistic variables. The rule-base combines the effort of fuzzy inference engine to modify the input linguistic variables. At the output stage, center of area COA is used as deffuzification method to calculate the weighted average of the fuzzy set and convert the linguistic output to crisps for computation of intensity levels of the disease.

\subsection{Dataset Descriptions}

The dataset for Hepatitis B was obtained from CarnegieMellon University database, Yugoslavia. It was donated by Jozef Stefan Institute. It consists of 20 attributes having total number of 155 instances. For the purpose of this research, the interpretation and analysis of the five selected attributes was carried out by hematologists. The five attributes used as input parameters are Ascites, Bilirubin, Alk-Phosphate, SGOT, and Albumin while Histology attribute was used as output. The output field is classified as mild and severe.

\subsection{Linguistic Variables with Range Limits and Corresponding Values}

The input variables are important parameters of the dataset which are investigated to form basis for disease diagnosis. In this study, two medical experts that specialize in liver disease diagnosis, offered assistance in analyzing the attributes in the dataset and designed fuzzy membership expressions for hepatitis as presented in Table 2.

\subsection{Preprocessing of linguistic values (Input parameters)}

Transformation of attributes values into more meaningful values that can sustain and maintain numerical stability to produce best optimal solution is highly needed before the commencement of simulation on those data. This process is referred to as Normalization. It is essential to re-scale all the attributes values in the dataset into the range of 0 and 1 by using the formula below:

$$
\mathrm{X}_{\text {new }}=\left(\left(\mathrm{X}-\mathrm{X}_{\min }\right) /\left(\mathrm{X}_{\max }-\mathrm{X}_{\min }\right)\right)
$$

Where $\mathrm{x}=$ the real value in the column

$\mathrm{x}_{\min }=$ the lowest value in column

$\mathrm{x}_{\max }=$ the highest value in the column

$\mathrm{x}_{\text {new }}=$ the normalized value

\subsection{Neuro-Fuzzy engine i.e. ANFIS}

The proposed model adopted ANFIS The combination of advantages of neural-network and fuzzy system are integrated to produce hybrid system that can learn, adapt and deal with large amount of imprecise numerical data.

Algorithm Header: ANFIS_Components ()

The ANFIS-based algorithm developed for the proposed model is given below

Step 1: Input FIS parameter parameters: mf, mftype, epochMax, errorGoal, iniStep

$$
\begin{aligned}
& \text { no_mf }:=3 \\
& \text { mf_type }:=\text { gaussmf } \\
& \text { epoch_max }:=200 \\
& \text { error_goal }:=0 \\
& \text { initial_step_size }:=0.01
\end{aligned}
$$

Step 2: Execution of normalization function by using Equation below

$$
\mathrm{X}_{\text {new }}=\left(\left(\mathrm{X}-\mathrm{X}_{\min }\right) /\left(\mathrm{X}_{\max }-\mathrm{X}_{\min }\right)\right)
$$

Step 3: Input percentage value for training dataset and testing dataset

Step 4: Neural Network is invoked to provide structures for Fuzzy Inference Engine FIS to learn information about the normalized dataset.

Step 5: NN will triggers backpropagation algorithm and least square methods to tune membership functions at the fuzzification stage

Step 6: The rule-base combines the effort of FIS to modify the input linguistic variables while Gaussian membership

\begin{tabular}{|c|c|c|c|c|c|c|}
\hline $\mathbf{S} / \mathbf{N}$ & Authors & Years & $\begin{array}{l}\text { Input } \\
\text { Parameters }\end{array}$ & $\begin{array}{l}\text { Methods } \\
\text { Or Technique }\end{array}$ & $\begin{array}{l}\text { Output } \\
\text { Descriptions }\end{array}$ & $\underset{\%}{\text { Accuracy }}$ \\
\hline \multirow[t]{3}{*}{1} & \multirow{3}{*}{ Ayushi et al. } & 2017 & \multirow{3}{*}{$\begin{array}{l}\text { LFT(Liver } \\
\text { Function } \\
\text { Tests) }\end{array}$} & $\begin{array}{l}\text { SVM (Support } \\
\text { Vector Machine }\end{array}$ & \multirow{3}{*}{$\begin{array}{l}\text { Presence \& Non-presence } \\
\text { of hepatitis }\end{array}$} & 83.16 \\
\hline & & 2017 & & $\begin{array}{l}\text { KSVN (Kernel } \\
\text { Support Vector } \\
\text { Machine) }\end{array}$ & & 85.16 \\
\hline & & 2017 & & KKNN & & 84.14 \\
\hline 2 & Vaidya et al. & 2017 & LFTs & Neuro-Fuzzy & $\begin{array}{l}\text { Healthy \& Non-healthy of } \\
\text { liver }\end{array}$ & $\begin{array}{l}\text { Not } \\
\text { considered }\end{array}$ \\
\hline 3 & $\begin{array}{l}\text { Ferokhzad } \\
\& \text { Ebrahimi }\end{array}$ & 2016 & LFTs & $\begin{array}{l}\text { Neuro-Fuzzy } \\
\text { (ANFIS) }\end{array}$ & $\begin{array}{l}\text { Healthy \& Non-healthy of } \\
\text { liver }\end{array}$ & 83 \\
\hline
\end{tabular}
function is used to design the fuzzy sets for the variables as presented in equation below

$\mu_{\mathrm{Ai}}(\mathrm{x})=\exp \left(-\left(\left(\mathrm{c}_{\mathrm{i}}-\mathrm{x}\right)^{2} /\left(2 \sigma_{\mathrm{i}}^{2}\right)\right)\right.$

Where $c_{i}$ represents the centre, $\partial_{i}$ represents the width of the ith fuzzy set $\mathrm{A}^{\mathrm{i}}$

Table 1: Overview of AI techniques used for liver diagnosis 


\begin{tabular}{|c|c|c|c|c|c|c|}
\hline 4 & $\begin{array}{l}\text { Obayya et } \\
\text { al. }\end{array}$ & 2016 & LFTs & ANFIS & $\begin{array}{l}\text { Healthy \& Non-healthy of } \\
\text { liver }\end{array}$ & 90 \\
\hline 5 & Cetin et al. & 2015 & LFTs & $\begin{array}{l}\text { ANN (Artificial } \\
\text { Neural } \\
\text { Network) }\end{array}$ & $\begin{array}{l}\text { Presence \& Non presence } \\
\text { of hepatitis }\end{array}$ & 91.9 \\
\hline 6 & $\begin{array}{l}\text { Rajamani } \\
\text { and Rathika }\end{array}$ & 2015 & LFTs & ANFIS & $\begin{array}{l}\begin{array}{l}\text { Prediction of presence } \\
\text { liver cancer }\end{array} \\
\end{array}$ & $\begin{array}{l}\text { Not } \\
\text { considered }\end{array}$ \\
\hline 7 & $\begin{array}{l}\text { Satarkar \& } \\
\text { Ali }\end{array}$ & 2014 & LFTs & Fuzzy Logic & $\begin{array}{l}\text { Classification of cirrhosis } \\
\text { disease into (low, } \\
\text { immediate, high) }\end{array}$ & $\begin{array}{l}\text { Not } \\
\text { considered }\end{array}$ \\
\hline 8 & Kulluk et al. & 2013 & LFTs & ANN and FL & $\begin{array}{l}\text { Healthy \& Non-healthy of } \\
\text { liver }\end{array}$ & 85.6 \\
\hline 9 & $\begin{array}{l}\text { Olaniyi } \quad \& \\
\text { Adnan }\end{array}$ & 2013 & LFTs & ANN & $\begin{array}{l}\text { Healthy \& Non-healthy of } \\
\text { liver }\end{array}$ & 63.0 \\
\hline 10 & Chang et al. & 2010 & LFTs & $\begin{array}{l}\text { Integration of } \\
\text { CBR, DM, FL } \\
\text { and GA }\end{array}$ & $\begin{array}{l}\text { Healthy \& Non-healthy of } \\
\text { liver }\end{array}$ & 81.6 \\
\hline 11 & Li \& Liu & 2010 & LFTs & ANN and FL & $\begin{array}{l}\text { Presence \& Non presence } \\
\text { of hepatitis }\end{array}$ & 70.78 \\
\hline 12 & Atiya et al. & 2009 & LFTs & KNN & $\begin{array}{l}\text { Presence \& Non presence } \\
\text { of hepatitis }\end{array}$ & 75 \\
\hline 13 & $\begin{array}{l}\text { Neshat \& } \\
\text { Yaghobi }\end{array}$ & 2009 & LFTs & ANFIS & $\begin{array}{l}\text { Presence \& Non presence } \\
\text { of hepatitis }\end{array}$ & 96.4 \\
\hline 14 & Neshat et al. & 2008 & LFTs & FL & $\begin{array}{l}\text { Presence \& Non presence } \\
\text { of hepatitis }\end{array}$ & 91.0 \\
\hline
\end{tabular}

Step 7: Membership functions and associated parameters map inputs through the output membership function and associated parameters to output.

Step 8: Gradient vector facilitated adjustment of the parameters associated with membership functions to enhance effective modeling of input/output data for every set of specific parameters.

Step 9: Deffuzifier uses equation below to convert the linguistic output to crisps. Center of Area or Centroid (COA), COA method was adopted to calculate the weighted average of the fuzzy set in the system

Step 10: Algorithm terminates

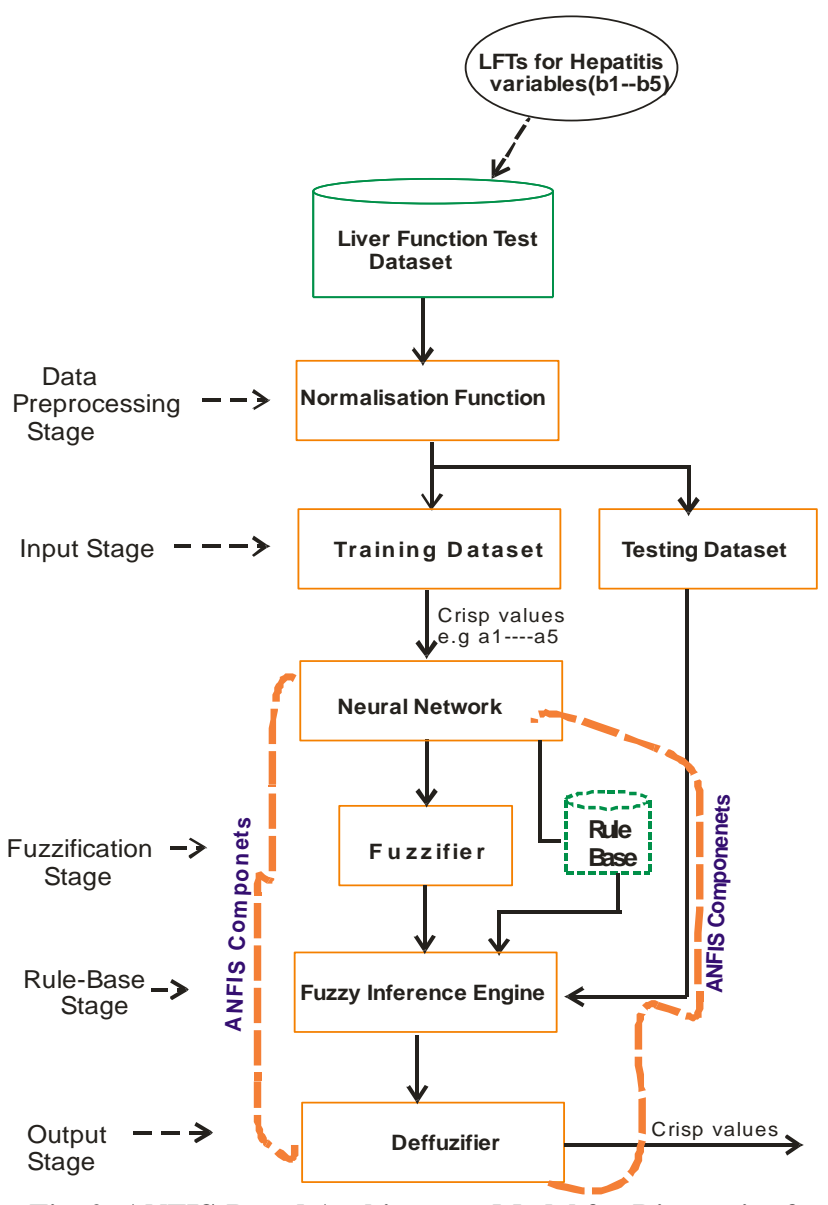

Fig. 2: ANFIS-Based Architecture Model for Diagnosis of Hepatitis B disease 
Table 2: Description of linguistic variables for Hepatitis B

\begin{tabular}{|c|c|c|c|c|}
\hline $\mathbf{S} / \mathbf{N}$ & $\begin{array}{l}\text { Input } \\
\text { Variables }\end{array}$ & Description & Moderate & Severe \\
\hline 1 & $\begin{array}{l}\text { Total } \\
\text { Bilirubin }\end{array}$ & $\begin{array}{l}\text { Blood test to measure abile } \\
\text { pigment cleared from the blood } \\
\text { by the liver }\end{array}$ & $\begin{array}{l}11 \leq X \leq \\
45\end{array}$ & $45<X$ \\
\hline 2 & $\begin{array}{l}\text { Alk- } \\
\text { Phosphates }\end{array}$ & $\begin{array}{l}\text { Test to measure quantity of blood } \\
\text { protein found in bile duct cell } \\
\text { membranes. }\end{array}$ & $\begin{array}{l}40 \leq X \leq \\
60\end{array}$ & $60<X$ \\
\hline 3 & SGOT & $\begin{array}{l}\text { Test to measure enzymes that } \\
\text { catalyze protein transformations } \\
\text { within hepatocytes }\end{array}$ & $\begin{array}{l}30 \leq X \leq \\
50\end{array}$ & $50<X$ \\
\hline 4 & Albumin & $\begin{array}{l}\text { Test to measure a protein in the } \\
\text { serum that transports substances. }\end{array}$ & $\begin{array}{l}28 \leq X \leq \\
35\end{array}$ & $28>X$ \\
\hline 5 & Ascites & $\begin{array}{l}\text { Clinical test to examine if liver is } \\
\text { perfectly working. }\end{array}$ & $1 \leq X \leq 4$ & $4<X$ \\
\hline
\end{tabular}

\section{METRICS USED TO EVALUATE THE MODEL PERFORMANCE}

The performance of the developed model, GADMLD, is evaluated by using confusion matrix. Confusion matrix is used in order to predict the number of correct and incorrect prediction made generated by the model when compared to the actual outcomes (target value) in the data.

a. TP (True Positive): When the outcome is appropriately classified as positive when it is really positive.

b. TN (True Negative): When the outcome is appropriately classified as negative when it is really negative.

c. FP (False Positive): When the outcome is incorrectly classified as positive when it is really negative.

d. FN (False Negative): When the outcome is appropriately classified as negative when it is really positive.

e. Accuracy: This is the measure that gives the proportion of the total number of predictions that were correct.

f. Precision: This is the proportion of positive cases that were correctly identified.

g. Sensitivity: This refers to the proportion of actual positive cases which are correctly identified.

h. Specificity: This explains the proportion of actual negative cases which are correctly identified.

\section{IMPLEMENTATION AND DISCUSSION OF RESULTS}

\subsection{Implementation}

The architecture model was simulated with MathLab 2015 version. Out of 164 total data used, only $40 \%$ of 164 (66) are used for training. After it was trained for 200 epochs, the following results are generated and also indicated in Figure 3.

MSE (Mean Square Error) $=0.11768$

RMSE (Root Mean Square Error) $=0.34305$

Error Mean $=-3.143 e-005$

Error St.D $=0.34567$

The MSE is interpreted as the measure of closeness of an output line to the specified data point (target line). The RMSE is computed as an average of distance between the target line and output line along the vertical line while the Error Mean measures the accuracy of the model. 


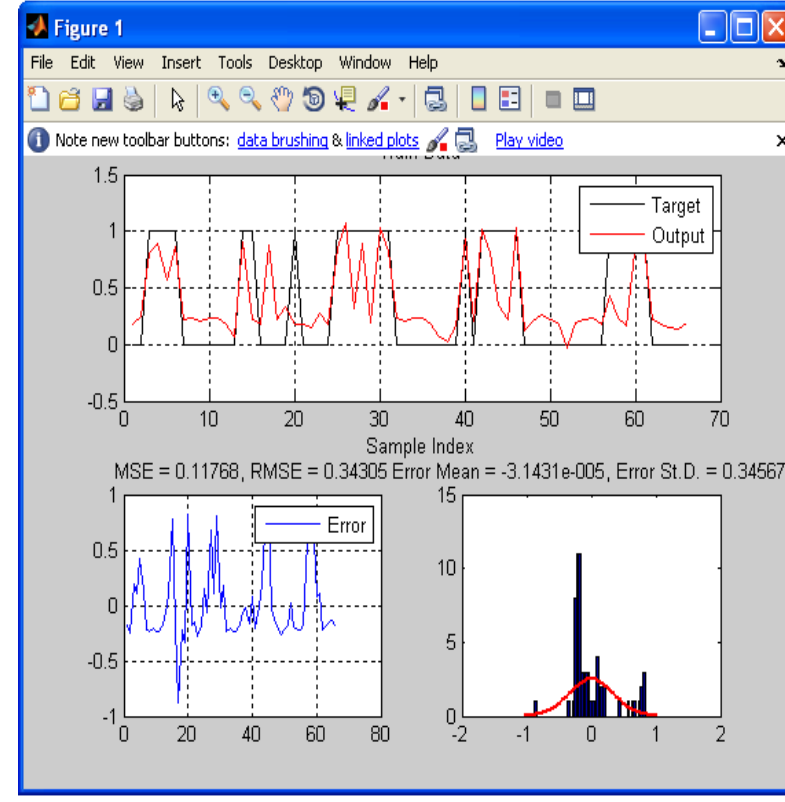

Fig. 3: Graph of Simulation Result of Hepatitis Dataset Training

$60 \%$ of the total numbers of 164 records (i.e. 98 records) in the dataset were selected randomly for testing and evaluating the proposed model, the simulated graph result is presented in Fig. 4. The following results are generated as follows;

MSE (Mean Square Error) $=0.28756$

RMSE (Root Mean Square Error) $=0.53625$

Error Mean $=0.1215$

Error St.D $=0.52498$

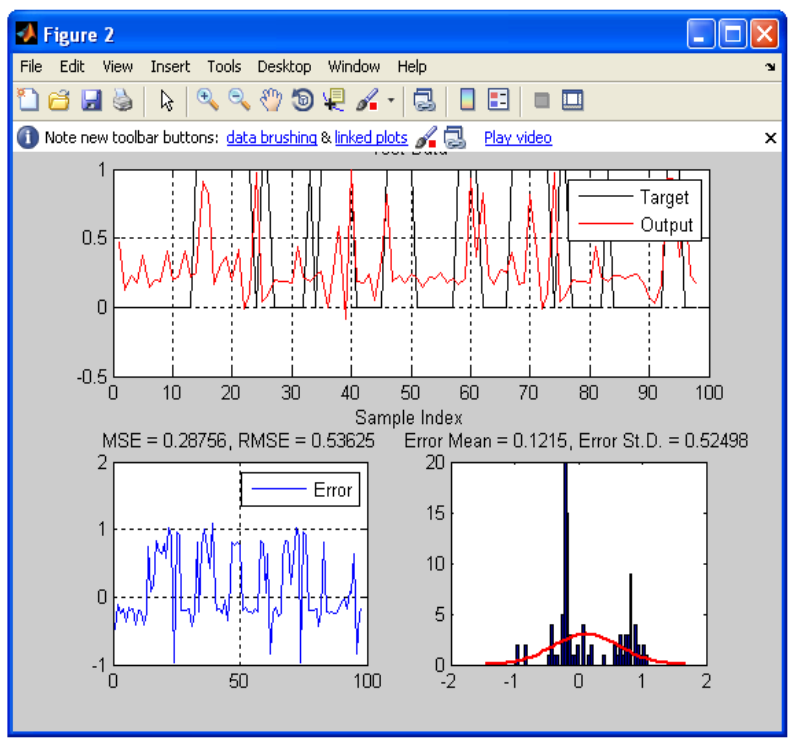

Fig. 4: Graph of Simulation Result of Hepatitis Dataset Training

\subsection{Discussion of Results}

In the course of simulation, 66 records were subjected for training the model, the output-target-error result generated is presented in Table 3 while 98 records were used to test the model and its output-target-error result is equally shown in Table 4 and Table 5 depicts the final output which generates
Linguistic Value, Further Linguistic Value and Intensity Level.

It is clearly presented in Table 5 that out of 56 records of patients that have moderate hepatitis B infection, only 26 of them have moderate-low while 30 patients have moderatehigh. Total number of 38 patients has severe infection, only 12 of them have severe-low and 26 patients have severe-high. This provides decision support services for doctors and medical practitioners for best optimal treatment to be administered on such patients. The $90.2 \%$ accuracy of the model obtained justifies the efficiency of ANFIS technique in building a medical decision system support for liver diseases diagnosis.

From Table 6, the original input parameters are the following attributes; Ascites, Bili, AlkPho, Alb, and SGOT. "Stage" as an attribute is the output classified as "1" and " 2 ", where " 1 " represents moderate and " 2 " represents severe. Each record has its own input parameters and corresponding output. After the simulation, the extent of the infection is generated for clarity and to remove imprecise information. For Example, record 1 and record 6 have the same Further Linguistic values of "Moderate High" but the Intensity Level of record 1 is 9.1857 and record 6 has 2.2268, likewise for record 14 and record 15.

Table 3: Result on Dataset-Training

\begin{tabular}{|l|l|l|l|}
\hline S/N & TARGET & OUTPUT & ERROR \\
\hline 1 & 0 & 0.172052829 & -0.172052829 \\
\hline 2 & 0 & 0.245701077 & -0.245701077 \\
\hline 3 & 1 & 0.810972348 & 0.189027652 \\
\hline 4 & 1 & 0.89484333 & 0.10515667 \\
\hline 5 & 1 & 0.57252434 & 0.42747566 \\
\hline 6 & 1 & 0.87038497 & 0.12961503 \\
\hline 7 & 0 & 0.227101621 & -0.227101621 \\
\hline 8 & 0 & 0.229706666 & -0.229706666 \\
\hline 9 & 0 & 0.207872243 & -0.207872243 \\
\hline 10 & 0 & 0.229121639 & -0.229121639 \\
\hline 11 & 0 & 0.240717178 & -0.240717178 \\
\hline 12 & 0 & 0.172564037 & -0.172564037 \\
\hline 13 & 0 & 0.070823708 & -0.070823708 \\
\hline 14 & 1 & 0.908139745 & 0.091860255 \\
\hline 15 & 1 & 0.220518428 & 0.779481572 \\
\hline 16 & 0 & 0.181018529 & -0.181018529 \\
\hline 17 & 0 & 0.877377191 & -0.877377191 \\
\hline 18 & 0 & 0.219340721 & -0.219340721 \\
\hline 19 & 0 & 0.338961716 & -0.338961716 \\
\hline 20 & 1 & 0.178932845 & 0.821067155 \\
\hline 21 & 0 & 0.173962716 & -0.173962716 \\
\hline 22 & 0 & 0.147404718 & -0.147404718 \\
\hline 23 & 0 & 0.27752971 & -0.27752971 \\
\hline 24 & 0 & 0.174462961 & -0.174462961 \\
\hline 25 & 1 & 0.847957056 & 0.152042944 \\
\hline 26 & 1 & 1.067108052 & -0.067108052 \\
\hline 27 & 1 & 0.321949661 & 0.678050339 \\
\hline. &. &. &. \\
\hline. &. &. &. \\
\hline 66 & 0 & 0.19478625 & -0.19478625 \\
\hline & & & \\
\hline & & & \\
\hline & & & \\
\hline & & & \\
\hline
\end{tabular}


Table 4: Result on Dataset-Testing

\begin{tabular}{|l|l|l|l|}
\hline S/N & TARGET & \multicolumn{1}{|c|}{ OUTPUT } & ERROR \\
\hline 1 & 0 & 0.470348439 & -0.470348439 \\
\hline 2 & 0 & 0.119738724 & -0.119738724 \\
\hline 3 & 0 & 0.233716924 & -0.233716924 \\
\hline 4 & 0 & 0.181760125 & -0.181760125 \\
\hline 5 & 0 & 0.371633188 & -0.371633188 \\
\hline 6 & 0 & 0.143992788 & -0.143992788 \\
\hline 7 & 0 & 0.193501173 & -0.193501173 \\
\hline 8 & 0 & 0.184739691 & -0.184739691 \\
\hline 9 & 0 & 0.406187582 & -0.406187582 \\
\hline 10 & 0 & 0.20111305 & -0.20111305 \\
\hline 11 & 0 & 0.214241352 & -0.214241352 \\
\hline 12 & 0 & 0.406953462 & -0.406953462 \\
\hline 13 & 0 & 0.217521825 & -0.217521825 \\
\hline 14 & 1 & 0.248443324 & 0.751556676 \\
\hline 15 & 1 & 0.912254832 & 0.087745168 \\
\hline 16 & 1 & 0.830294022 & 0.169705978 \\
\hline 17 & 1 & 0.16598022 & 0.83401978 \\
\hline 18 & 1 & 0.315385802 & 0.684614198 \\
\hline 19 & 1 & 0.360653132 & 0.639346868 \\
\hline 20 & 1 & 0.202366181 & 0.797633819 \\
\hline 21 & 1 & 0.416180083 & 0.583819917 \\
\hline 22 & 1 & -0.015170608 & 1.015170608 \\
\hline 23 & 1 & 0.104887081 & 0.895112919 \\
\hline 24 & 0 & 0.977267874 & -0.977267874 \\
\hline 25 & 1 & 0.039368997 & 0.960631003 \\
\hline 26 & 1 & 0.081119359 & 0.918880641 \\
\hline 27 & 0 & 0.199326506 & -0.199326506 \\
\hline. &. &. &. \\
\hline. &. &. &. \\
\hline 98 & 0 & -0.161426438 & 0.161426438 \\
\hline & & & \\
\hline & & & \\
\hline & & 0 & \\
\hline
\end{tabular}

In Table 3 and Table 4, the difference between the Target value and Output value which is computed as Error in each record is mostly found to be 0.1 . These are minimal errors that justify better performance of the model.

Table 5: Summary of Cumulative Intensity Rate for Hepatitis

\begin{tabular}{|c|c|c|c|c|}
\hline & & Low & High & \\
\hline \multirow[t]{2}{*}{ Hepatitis } & Moderate & & & \multirow{2}{*}{$\begin{array}{l}\text { Total }= \\
98\end{array}$} \\
\hline & & $\frac{26}{15}$ & $\frac{30}{26}$ & \\
\hline
\end{tabular}

The performance of the proposed model based on the metrics used is presented in Table 7. The accuracy of $90.2 \%$ was obtained after evaluation with the liver disease dataset.

Table 6: Final Simulated Result for Testing-Records

\begin{tabular}{|l|l|l|l|l|l|l|l|l|l|}
\hline S/N & Ascites & Bili & $\begin{array}{l}\text { ALK } \\
\text { Pho }\end{array}$ & SGOT & Alb & Stage & $\begin{array}{l}\text { Linguistic } \\
\text { Value }\end{array}$ & $\begin{array}{l}\text { Further } \\
\text { Linguistic }\end{array}$ & $\begin{array}{l}\text { Intensity } \\
\text { Level }\end{array}$ \\
\hline 1 & 2 & 0.9 & 76 & 271 & 4.4 & 1 & Moderate & Mod-High & 9.1857 \\
\hline 2 & 2 & 1 & 45 & 4 & 5 & 1 & Moderate & Mod-High & 7.9161 \\
\hline 3 & 2 & 1.5 & 100 & 100 & 5 & 1 & Moderate & Mod-High & 7.4598 \\
\hline 4 & 2 & 1 & 55 & 45 & 4.1 & 1 & Moderate & Mod-High & 9.1445 \\
\hline 5 & 2 & 2 & 167 & 242 & 3 & 1 & Moderate & Mod-High & 6.4017 \\
\hline 6 & 2 & 0.6 & 30 & 24 & 4 & 1 & Moderate & Mod-Low & 2.2628 \\
\hline 7 & 2 & 1 & 72 & 46 & 4.4 & 1 & Moderate & Mod-Low & 2.6026 \\
\hline 8 & 2 & 0.7 & 85 & 31 & 4.9 & 1 & Moderate & Mod-High & 8.5223 \\
\hline 9 & 2 & 0.7 & 62 & 224 & 4.2 & 1 & Moderate & Mod-High & 6.7432 \\
\hline 10 & 2 & 0.7 & 100 & 31 & 4 & 1 & Moderate & Mod-Low & 4.5115 \\
\hline 11 & 2 & 1.5 & 179 & 69 & 2.9 & 1 & Moderate & Mod-High & 6.9683 \\
\hline 12 & 2 & 1.3 & 141 & 156 & 3.6 & 1 & Moderate & Mod-Low & 3.245 \\
\hline 13 & 2 & 1.6 & 44 & 123 & 4.1 & 1 & Moderate & Mod-High & 7.0896 \\
\hline 14 & 2 & 0.9 & 135 & 55 & 4 & 2 & Severe & Sev-High & 75.1557 \\
\hline 15 & 1 & 2.5 & 165 & 64 & 2.8 & 2 & Severe & Sev-Low & 8.7745 \\
\hline 16 & 1 & 1.2 & 118 & 16 & 2.8 & 2 & Severe & Sev-Low & 16.9706 \\
\hline 17 & 2 & 0.6 & 76 & 18 & 4.4 & 2 & Severe & Sev-High & 83.402 \\
\hline 18 & 2 & 0.9 & 230 & 117 & 3.4 & 2 & Severe & Sev-High & 68.4614 \\
\hline 19 & 2 & 1.5 & 107 & 157 & 3.4 & 2 & Severe & Sev-Low & 63.9347 \\
\hline
\end{tabular}




\begin{tabular}{|l|l|l|l|l|l|l|l|l|l|}
\hline 20 & 2 & 0.6 & 40 & 69 & 4.2 & 2 & Severe & Sev-High & 79.7634 \\
\hline$\cdot$ & $\cdot$ & $\cdot$ & $\cdot$ & $\cdot$ & $\cdot$ & $\cdot$ & $\cdot$ & $\cdot$ & $\cdot$ \\
\hline$\cdot$ & $\cdot$ & $\cdot$ & $\cdot$ & $\cdot$ & $\cdot$ & $\cdot$ & $\cdot$ & $\cdot$ & $\cdot$ \\
\hline 98 & 2 & 0.7 & 71 & 18 & 4.4 & 1 & Moderate & Mod-High & 8.5482 \\
\hline
\end{tabular}

Table 7: The Performance Evaluation Metrics used

\begin{tabular}{|l|l|l|l|l|l|l|l|l|l|}
\hline $\begin{array}{l}\text { Performance } \\
\text { Metrics }\end{array}$ & TP & TN & FP & FN & $\begin{array}{l}\text { False } \\
\text { Positive } \\
\text { Rate }\end{array}$ & $\begin{array}{l}\text { Specificity } \\
\%\end{array}$ & $\begin{array}{l}\text { Precision } \\
\%\end{array}$ & $\begin{array}{l}\text { Sensitivity } \\
\%\end{array}$ & $\begin{array}{l}\text { Accuracy } \\
\%\end{array}$ \\
\hline Hepatitis & 57 & 32 & 0 & 8 & 0 & 1 & 100 & 87.69 & $\mathbf{9 0 . 2}$ \\
\hline
\end{tabular}

\section{CONCLUSION}

In this study, we have been able to develop an architecture model that combines the knowledge-base and reasoning features of fuzzy logic (FL), with self-learning capacity of artificial neural network (ANN) to diagnose Hepatitis B disease by computing the intensity levels of its attack. Medical field refers to diagnosis as an approach of recognizing a disease through the analysis of underlying physiological symptoms. Hepatitis is a chronic liver disease that can easily decompensate to cirrhosis disease if its severity is not properly checked with appropriate tools. This study can improve the quality of liver disease diagnosis and provide appropriate information for medical practitioners in the process of administering treatment. This work could be further expanded for improved optimal solutions by integrating Genetic Algorithm (GA) with ANFIS.

\section{ACKNOWLEDGEMENT}

The authors appreciate the efforts of Dr Gundirin and Dr Sini, at Federal Medical Centre, Yola, Adamawa State .

\section{REFERENCES}

[1] Atiya, A.F., and Al-Ani, A. (2009): "A penalized likelihood based pattern classification algorithm". Pattern Recognition, Vol. 42, No. 11, pp. 2684-2694.

[2] Ayushi, S., Sharma, V., \& Gupta, R. (2017): "Liver Disease Prognosis Based on Clinical Parameters Using Machine Learning Approach". International Journal for Research in Applied Science \& Engineering Technology (IJRASET), Vol. 5, No. 6.

[3] Bahramirad, S., Mustapha, A., and Eshraghi, M. (2013): "Classification of Liver Disease Diagnosis: A Comparative Study". Second International Conference on Informatics and Applications 23-25 ${ }^{\text {th }}$ Sep., pp. $42-46$

[4] Çetin, O., Temurtaş, F. and Gulgonul, S. (2015): "An application of multilayer neural network on hepatitis disease diagnosis using approximations of sigmoid activation function”. Dicle Medical Journal, Vol. 42, No 2. pp. $150-157$.

[5] Chang, P.C., Fan, C.Y. and Dzan, W.Y. (2010). "A CBR-based fuzzy decision tree approach for

database classification", Expert Systems with Applications, Vol. 37, No. 1, pp.214-225

[6] Farokhzad M., and Ebrahimi, L. (2016). "A Novel Adaptive Neuro Fuzzy Inference System for the Diagnosis of Liver Disease". International Journal of Academic Research in Computer Engineering, Vol. 1, No. 1, pp. 61-66.
[7] Friedman S. (2004). "On the use and usefulness of fuzzy sets in medical AI, Artificial Intelligence in Medicine". Vol. 21, pp 131-137.

[8] Jang, J.S.R. (1993): "Anfis adaptive-network-based fuzzy inference system".Systems, Man and Cybernetics, IEEE Transactions on, Vol.23, pp. 665-685.

[9] Karthikkalyan, K. (2014) "Artificial Neural Network Application in the Diagnosis of Disease condition with Liver Ultrasound Images", Article ID. 708279, 14 pages.

[10] Kulluk, S., Ozbakır, L. and Baykasoglu, A. (2013). "Fuzzy DIFACONN-miner: a novel approach for fuzzy rule extraction from neural networks". Expert Systems with Applications, Vol. 40, No. 3, pp. 938-946.

[11] Li, D.C. and Liu, C.W. (2010). "A class possibility based kernel to increase classification accuracy for small data sets using support vector machines". Expert Systems with Applications, Vol. 37, No. 4, pp 3104-3110

[12] Negnevitsky, M. (2005). "Artificial Intelligence: a guide to intelligent systems". Pearson

Education Limited, Essex, England

[13] Neshat, M. and Zadeh, A.E. (2013): "Hopfield neural network and fuzzy Hopfield neural network for diagnosis of liver disorders". 5th IEEE International Conference on Intelligent Systems (IS), London, pp. 162-167.

[14] Neshat, M. and Yaghobi, M. (2009): “ Designing a Fuzzy Expert System of Diagnosing the Hepatitis B Intensity Rate and Comparing it with Adaptive Neural Network Fuzzy System". Proceedings of the World Congress on Engineering and Computer Science, San Francisco, USA. Vol. 2 no. 48, 2010, pp. 48-65

[15] Neshat, M., Yaghobi, M., Naghibi, B. and Esmaelzadeh, A. (2008). "Fuzzy Expert System Design for Diagnosis of liver disorders". International Symposium on Knowledge Acquisition and Modeling

[16] Obayya, I.M., Areed, N.F, and Abdulhadi, A.O. (2016): "Liver Cancer Identification using Adaptive NeuroFuzzy Inference System". International Journal of Computer Applications Vol. 140, No.8

[17] Obi J.C. and Imianvan, A.A. (2011). "Interactive NeuroFuzzy Expert System for Diagnosis of leukemia". Global Journal of Computer Science and Technology,USA. Volume 11, No.12

[18] Olaniyi, E.O. and Adnan, K. (2013): "Onset diabetes diagnosis using Artificial neural network". International Journal of Scientific and Engineering Research, Vol 5, pp 754-759. 
[19] Rajamani, R ., and Rathika, M. (2015). "Analysis of Liver Cancer using Adaptive Neuro Fuzzy Inference System (ANFIS)". International Journal of Innovative Research in Computer and Communication Engineering, Vol. 3, No 7

[20] Satarkar, S.L. and Ali, M.S. (2014). "Fuzzy Expert System for The Diagnosis of Common Liver Disease". International Engineering Journal for Research \& Development, Vol.1, No.1, pp. 1-7
[21] Smita, S., Sushil, S. and Ali, M.S. (2012). "Artificial Intelligence in Medical Diagnosis". International Journal of Applied Engineering Research, Vol.7, No.11

[22] Vaidya H., Chaudhari, S.K, and Ingale, H.T. (2017) "Neuro Fuzzy Based Liver Disease, Classification", Vol. 3 , No 4

[23] Yardimci, A. (2001): "Soft computing in medicine. Applied Soft Computing", Vol 9, pp. 1029 - 1043. 